\title{
A CALAGEM NA REAÇÃO DO ALGODOEIRO À ADUBAÇÃO COM SUPERFOSFATO SIMPLES (1)
}

\author{
NELSON MACHADO DA SILVA (2), LUZ HENRIQUE CARVALHO $(2,4)$, \\ RUTER HIROCE $(3)$ I JOSÉ ANTONIO QUAGGIO $(3,4)$
}

\begin{abstract}
RESUMO
Após o quarto ano de conduçâo de um ensaio permanente de calagem e de adubação mineral com o algodoeiro, iniciado em $1974 \mathrm{em}$ um latossolo roxo ácido, argiloso $(66 \%)$ e rico em matéria orgânica $(4,1 \%)$, no municlpio de Gualra, SP, reaplicou-se o calcário. Utilizaram-se as mesmas doses da primeira fase $(1,5,3,0$ e 6,0 t/ha), exceto nas parcelas testemunhas, onde se fez uma calagem minima com 1,5 t/ha. A adubaçăo mineral teve continuidade com aplicaçōes anuais de $60 \mathrm{~kg} / \mathrm{ha}$ de $\mathrm{N}$ (sulfato de amónio) e $\mathrm{P} \times \mathrm{K}$, em esquema fatorial, nas doses de 0,60 e $120 \mathrm{~kg} / \mathrm{ha}$ de $\mathrm{P}_{2} \mathrm{O}_{5}$ (superfosfato simples) e 40 e $80 \mathrm{~kg} / \mathrm{ha}$ de $\mathrm{K}_{2} \mathrm{O}$ (cloreto de potássio). Por falta de resposta significativa do algodoeiro a potássio, não se considerou 0 efeito do referido nutriente. No tratamento com a dose máxima de calcário, foi possivel estabilizar o pH em $\mathrm{H}_{2} \mathrm{O}$ na camada arável do solo, ao redor de $6,0 \mathrm{e}, \mathrm{em}$ funçāo da lixiviaçăo de bases $(\mathrm{Ca}+\mathrm{Mg}$ ), na faixa de 5,5 na camada subsuperficial, que representariam condiçöes adequadas para o desenvolvimento da cultura em apreço. $\mathrm{O}$ indice $\mathrm{pH}$, os valores de $\mathrm{Ca}$ e de $\mathrm{Mg}$ da análise de terra $e$ a produtividade das plantas cresceram significativamente com a reaplicaçăo do calcário. A resposta do algodoeiro à aplicação acumulada de superfosfato simples diminuiu com a correção da acidez do solo,
\end{abstract}

(1) Trabalho apresentado no XIX Congresso Brasileiro de Ciência do Solo, realizado em Curitiba (PR), de 17 a 27 de julho de 1983. Recebido para publicaçăo em 27 de janeiro de 1987.

(2) Seçăo de Algodăo, Instituto Agronômico (AC), Caixa Postal 28, 13001 Campinas (SP).

(3) Seçăo de Fetilidade do Solo e Nutrição de Plantas, IAC.

(4) Bolsista do CNPq. 
configurando típica interação negativa entre a adubação fosfatada e a calagem. O método da resina trocadora de ânions mostrou-se mais adequado na extração do fósforo do solo do que o do ácido sulfúrico diluído, tendo em vista não só a boa repetitividade dos resultados analfticos observada durante os quatro anos de estudos como também a estreita correlação obtida entre os teores de P-resina e os valores do indice pH da análise de terra. Decréscimos significativos na concentração de macronutrientes e de micronutrientes do limbo foliar do algodoeiro, devidos à calagem e à adubação fosfatada, confirmam a necessidade de se prevenir contra prováveis problemas que possam ocorrer, representados especialmente por deficiências de $\mathrm{K}$ e $\mathrm{B}$, na correção de solos ácidos e de baixa fertilidade.

Termos de indexação: calcário dolomftico; superfosfato simples; calagem e fósforo, correlação; lixiviaçāo de bases e análise foliar.

\section{INTRODUÇÃo}

A correção de solos ácidos para faixa de pH entre 6,0 e 7,0 tem sido comumente aceita como um importante fator para aumentar a disponibilidade de fósforo às plantas (TISDALE \& NELSON, 1975, e MENGEL \& KIRKBY, 1978). No caso do algodoeiro, observou-se que ele pode tornar-se menos exigente à adubação fosfatada após a devida correção do solo (MIKKELSEN et al., 1963) ou, ainda, que a eficiência dessa adubação pode dobrar em faixa adequada de $\mathrm{pH}$ (JONES \& BARDSLEY, 1968). Na cultura de soja, VIDOR \& FREIRE (1972) demonstraram a possibilidade de substituição de altas adubaçōes fosfatadas por adequadas calagens. Em acréscimo a esse inter-relacionamento, QUAGGIO et al. (1982) sugerem que a correção de camadas subsuperficiais do perfil do solo, através da calagem, possa proporcionar condições para maior aprofundamento das raizes das plantas e à exploração de um volume maior de solo em termos de absorção de nutrientes.

Na primeira fase do estudo de um ensaio permanente de calagem e adubação mineral do algodoeiro, SILVA et al. (1980) destacaram o efeito da aplicação de corretivo sobre o comportamento do algodão em solo ácido e pobre em fósforo. A despeito da dose máxima de calcário $(6 \mathrm{t} / \mathrm{ha})$ ter sido calcuiada para elevar o pH do solo à faixa de 6,0-7,0, esse índice não chegou a ser alcançado, observação confirmada por RAlJ et al. (1983). Por essa razão, talvez, não se tenha obtido valor estatístico significativo para a interação calagem $\mathrm{x}$ adubação fosfatada, embora freqüentemente as plantas tenham reagido menos a fósforo na presença de calcário. Decidiu-se, então, pela reaplicação do calcário após o quarto ano agrícola, dando prosseguimento ao estudo da referida inter-relação. Neste trabalho apresentam-se e discutem-se os resultados obtidos nos quatro anos subseqüentes à segunda calagem. 


\section{MATERIAL E MÉTODOS}

No ano agrícola de $1977 / 78$, considerou-se encerrado o primeiro ciclo do estudo de efeitos da calagem e da adubaçăo mineral sobre o algodoeiro cultivado em latossolo roxo, ácido, num ensaio permanente iniciado em 1974. Embora detalhes sobre material e métodos empregados se encontrem em trabalhos publicados por SILVA et al. (1980) e RAIJ et al. (1983), deve-se destacar que os tratamentos foram dispostos no campo experimental em parcelas subdivididas (calagem nas parcelas e fatorial $P \times K$ nas subparcelas), com quatro repetições.

Em junho de 1978, procedeu-se à nova calagem nas parcelas maiores, empregando-se as mesmas doses utilizadas anteriormente: 1,5, 3,0 e 6,0 t/ha de calcário dolomítico. Nas parcelas testemunhas, dessa vez, foi efetuada uma aplicação de 1,5 t/ha de calcário, visando dar condiçōes mínimas de sobrevivência ao algodoeiro.

Como na primeira etapa, empregou-se calcário dolomítico cuja análise revelou os seguintes resultados:

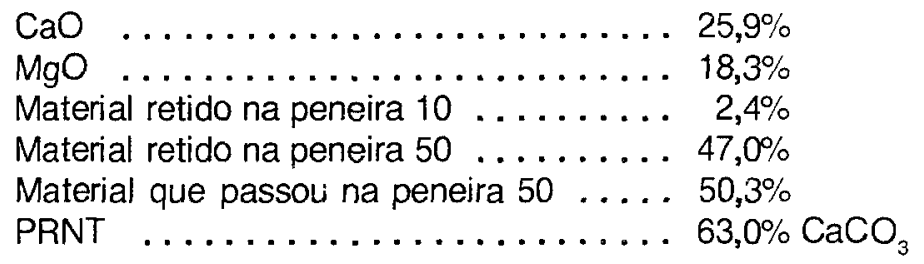

Nas subparcelas, $\mathrm{P}$ e $\mathrm{K}$ continuaram a ser fornecidos anualmente, em esquema fatorial, nas mesmas doses - 0,60 e $120 \mathrm{~kg} / \mathrm{ha}$ de $\mathrm{P}_{2} \mathrm{O}_{5}$ e 40 e $80 \mathrm{~kg} /$ /ha de $\mathrm{K}_{2} \mathrm{O}$ - pela aplicação de superfosfato simples e cloreto de potássio no sulco de plantio. Manteve-se constante a adubação nitrogenada, na base anual de $10 \mathrm{~kg} / \mathrm{ha}$ de $\mathrm{N}$, cedidos no plantio, e $50 \mathrm{~kg} / \mathrm{h}$ a no desbaste, em cobertura, na forma de sulfato de amônio. O experimento foi semeado com a variedade IAC 18.

Anualmente, coletaram-se amostras de solo por dose de calcário e por repetição, em duas e/ou três profundidades $(0-20,20-40$ e $40-60 \mathrm{~cm})$, para se observar a evolução da correção da acidez e a lixiviação de bases no solo, através do tempo. Durante a fase de intenso florescimento, aproximadamente aos 80 dias de idade das plantas, procedeu-se à coleta de limbos foliares para análise química, apenas no segundo e terceiro cultivos. A colheita de algodão em caroço, por sua vez, foi efetuada em duas etapas: antes da primeira, procedeu-se à amostragem casual de capulhos para estudos de laboratório, envolvendo sementes e fibra, cujos resultados deverão ser tema de outro trabalho. 


\section{RESULTADOS E DISCUSSÃO}

\subsection{Resultados de análise de solo}

Determinaçōes de $\mathrm{pH}$ em água, efetuadas em amostras de terra colhidas periodicamente, a duas profundidades, desde seis meses antes da segunda aplicação de calcário, permitiram avaliar, de certa forma, os efeitos da calagem através do tempo de açăo do corretivo. A figura 1 apresenta as variaçöes observadas no índice pH médio e os resultados de análises conjuntas de dados correspondentes a cinco amostragens de solo colhidas no periodo.

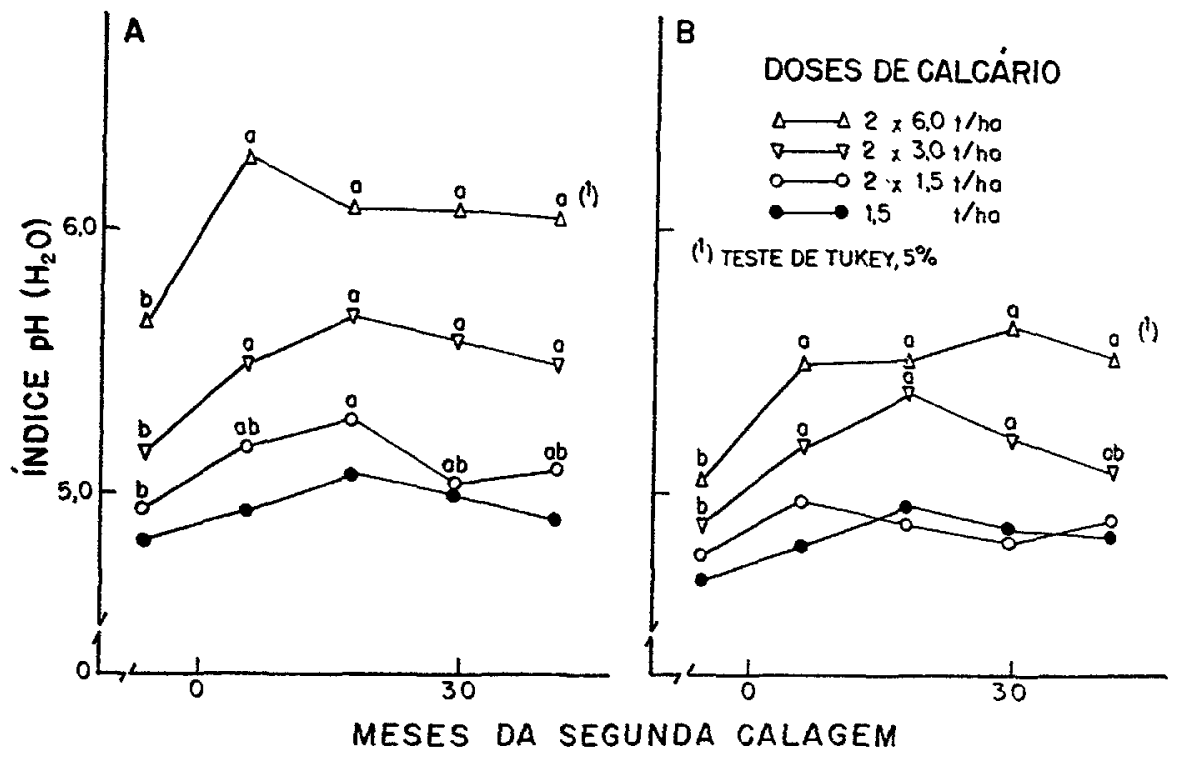

FIGURA 1. Variaçరes nos valores médios de $\mathrm{pH}$ em $\mathrm{H}_{2} \mathrm{O}$ do solo devidas à reaplicação de calcário, observadas através dos anos de condução do ensaio permanente de calagem com o algodoeiro: $A$ : profundidade de $0-20 \mathrm{~cm}(\mathrm{CV}=2,6 \%)$; e B: profundidade de 20 $-40 \mathrm{~cm}(\mathrm{CV}=2,4 \%)$. Teste de Tukey a $5 \%$.

Trabalhos anteriores (SILVA et al., 1980, e RAW et al., 1983) relatam que na camada superficial do solo, ao final da primeira fase do estudo, observaram-se os seguintes resultados analíticos, respectivamente, para as doses de 0 , $1,5,3,0 \in 6,0$ t/ha de calcário: 4,8, 4,9,5,2 e 5,7 para o indice $\mathrm{pH} \in \mathrm{m} \mathrm{H}_{2} \mathrm{O}$, e 17, 26,38 e $56 \%$ para a saturação por bases (V\%). Tendo em vista as quantidades 
utilizadas na segunda calagem e uma relação média entre $\mathrm{pH}$ e $\mathrm{V} \%$, de $\mathrm{pH}=4,5$ $+0,025 \mathrm{~V}$, conforme propõe RAIJ (1981), era esperado que o indice $\mathrm{pH}$ pudesse atingir, por nivel de calagem, valores máximos de 5,2,5,4,6,0 e 7,0. Na figura 1-A, observa-se que nas parcelas anteriormente mais ácidas, $\mathrm{com} \mathrm{pH}$ abaixo de 5,0 onde se usou dose de 1,5 t/ha de calcário, as correções esperadas (de 5,2 e 5,4 , para $\mathrm{pH}$ ) foram praticamente alcançadas na segunda amostragem, com valores respectivos de 5,1 e 5,3. Entretanto, nas parcelas menos ácidas, com pH igual ou acima de 5,2 , os valores máximos obtidos $(5,7$ e 6,3$)$ estiveram abaixo dos niveis esperados $(6,0$ e 7,0$)$. Provavelmente a explicação para esse fato esteja na redução da solubilidade do $\mathrm{CaCO}_{3}$ e $\mathrm{MgCO}_{3}$ em faixas de $\mathrm{pH}$ mais alto, associada à granulometria do calcário empregado. Isso explicaria, também, a maior estabilidade do $\mathrm{pH}$ nas doses máximas ao longo dos anos. Com efeito, somente nas doses mais elevadas a reaplicaçāo do calcário proporcionou, através do tempo, elevações estatisticamente significativas do $\mathrm{pH}$, tanto na camada arável do solo (Fig. 1-A) como na subsuperficial (Fig. 1-B). Ademais, nas parcelas que receberam dose máxima ( 2 × 6,0 t/ha de calcário), o pH da camada superficial permaneceu, durante todo o tempo, na faixa de 6,0 , e ao redor de 5,5 na profundidade de $20-40 \mathrm{~cm}$, condições comumente consideradas adequadas para bom desenvolvimento do sistema radicular do algodoeiro, conforme ADAMS (1968) e ADAMS et al. (1967).

As alteraçōes nos valores de $\mathrm{Ca}$ e de $\mathrm{Mg}$ no perfil do solo foram acompanhadas por análises de amostras colhidas inicialmente até à profundidade de 20-40 cm e, a partir do segundo ano agrícola (1979/80), até à de 40-60 cm. $\mathrm{Na}$ figura 2 acham-se os resultados de quatro diferentes períodos do estudo.

Antes da reaplicação do calcário (Fig. 2-A), o efeito residual da primeira calagem sobre os teores das referidas bases, na camada arável do solo, ainda era bern visivel. Já análises efetuadas sete meses após a segunda aplicação destacaram, também, o efeito da calagem na profundidade de $20-40 \mathrm{~cm}$, conforme valores respectivos de $\mathrm{Ca}+\mathrm{Mg}$ (Fig. 2-B).

Somente a partir do segundo ano (1979, ou seja, dezenove meses após a segunda aplicação de calcário, coletaram-se amostras de terra até à faixa de 40-60 cm, constatando-se aumento sensivel nos teores de bases, até a referida profundidade, em especial devido à maior dose de corretivo (Fig. 2-C). Essas diferenças praticamente persistiram até o quarto ano agrícola, 1981/82 (Fig. 2-D).

A lixiviação de bases através do perfil e a melhoria do $\mathrm{pH}$ em profundidade devem ter possibilitado um desenvolvimento maior do sistema radicular, segundo ADAMS (1968), ADAMS et al. (1967) e QUAGGIO et al. (1982). Em conseqüência, mais intenso aproveitamento de água e de nutrientes na faixa subsuperficial do solo acabou concorrendo para aumento da produtividade das plantas, como se verá. 

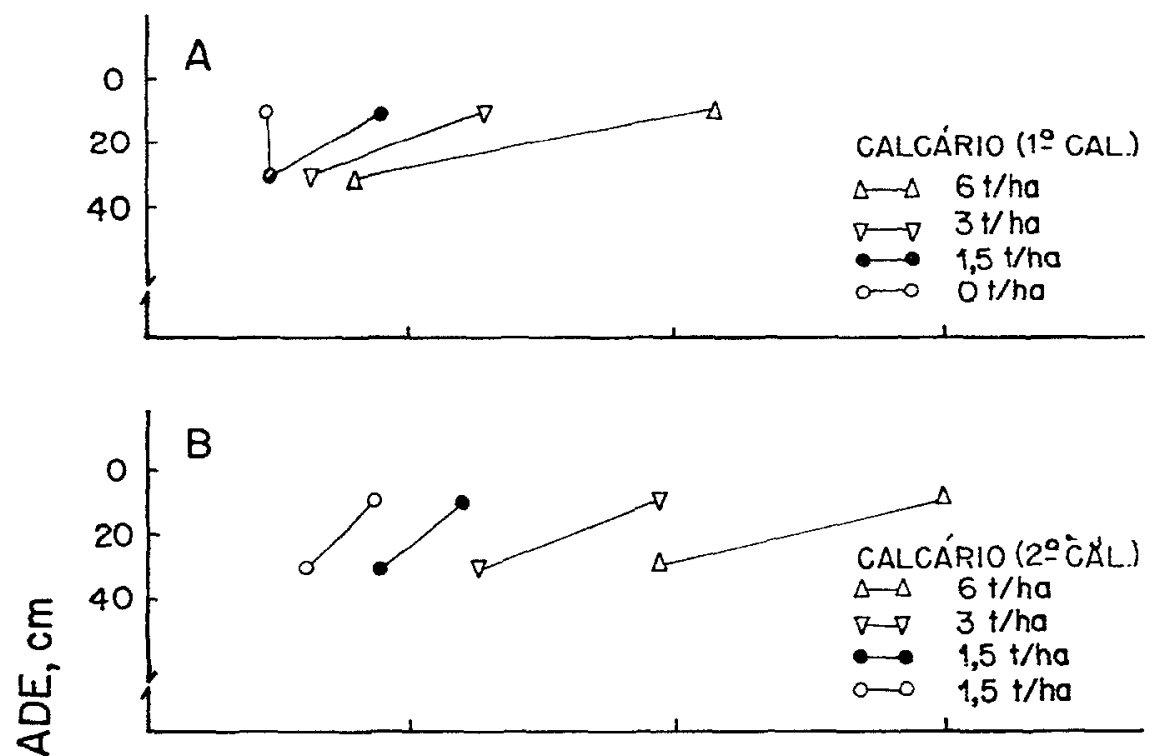

C
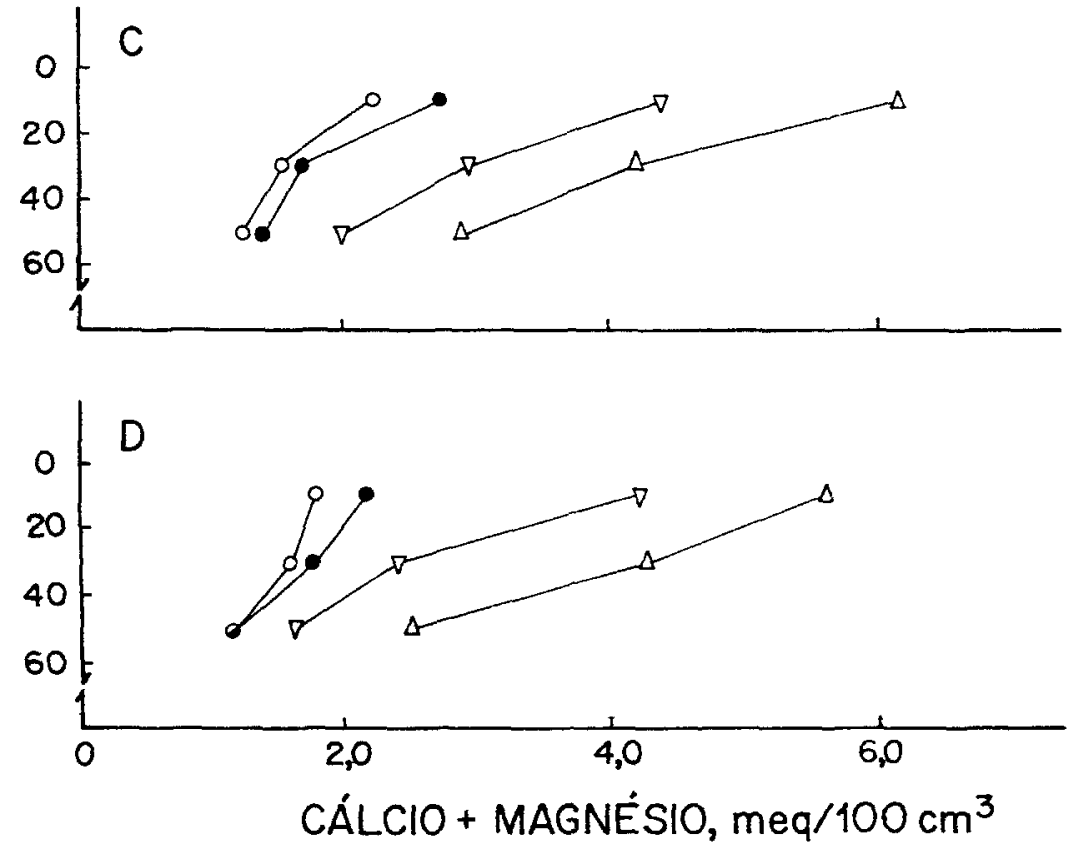

FIGURA 2. Lixiviação de cálcio mais magnésio no perfil do solo, em várias épocas de amostragem, em funçāo da calagem: A: 1978, antes da $2^{\text {a }}$ calagem; B: 1979, 7 meses após a $2^{\mathrm{a}}$ calagem; C: 1980,19 meses após a $2^{\mathrm{a}}$ calagem; D: 1982,43 meses após a $2^{\mathrm{a}}$ calagem. 
Um terceiro elemento relacionado com o problema de acidez do solo, que se deve considerar, é o aluminio trocável. Análises do periodo anterior (SILVA et al., 1980, e RAlJ et al., 1983) indicam baixo valor original na camada superficial, cerca de 1,0 meq de Al, e menor ainda nas camadas inferiores; indicam, também, que a menor dose de calcário empregada na primeira correção $(1,5 \mathrm{t} / \mathrm{ha})$ praticamente eliminou o Al tóxico. No quadro 1, acham-se os resultados obtidos após a reaplicação do corretivo, no primeiro, segundo e último ano do estudo.

Em linhas gerais, o panorama é semelhante ao da primeira fase. Na camada arável, o Al trocável mostrou-se inferior a 1,0 meq, mesmo no tratamento considerado testemunha, enquanto o efeito da calagem foi altamente significativo, eliminando por completo, e de forma persistente, o citado elemento nos niveis mais altos de correção. Entretanto, dose baixa de calcário (1,5 t/ha), aplicada em condição mais ácida, pouco alterou o valor do Al através dos anos, mesmo na camada arável. O valor médio de Al caiu nas camadas subsuperficiais do solo, mesmo nas parcelas testemunhas, o que deve representar uma característica natural do latossolo roxo em estudo.

O fósforo, por sua vez, foi extraído do solo pelo método do $\mathrm{H}_{2} \mathrm{SO}_{4} 0,05 \mathrm{~N}$, descrito por RAIJ \& ZULLO (1977) e, também, pela resina trocadora de ânions, de acordo com RAlJ et al. (1984), com 16 horas de tempo de extração. Alguns aspectos na análise comparativa dos dados obtidos - Quadro 2 - são a seguir considerados.

QUADRO 1. Efeitos da reaplicação de doses crescentes de calcário nos valores de Al trocável de amostras de solo extraldas em diversas camadas do perfil durante o perlodo de permanência do ensaio de calagem, em Gualra, SP

\begin{tabular}{|c|c|c|c|c|c|c|c|c|c|}
\hline \multirow{3}{*}{$\begin{array}{l}\text { Calcário } \\
\text { aplicado (1) }\end{array}$} & \multicolumn{9}{|c|}{ Al trocável, em análises anuais } \\
\hline & \multicolumn{3}{|c|}{$1978 / 79$} & \multicolumn{3}{|c|}{$1979 / 80$} & \multicolumn{3}{|c|}{$1981 / 82$} \\
\hline & $0-20(2)$ & $20-40$ & $40-60$ & $0-20$ & $20-40$ & $40-60$ & $0-20$ & $20-40$ & $40-60$ \\
\hline t/ha & & & & - & $e q / 100 c$ & $n^{3}$ & & & \\
\hline $0+1,5$ & $0,9 a(3)$ & $0,7 a$ & - & $0,9 a$ & $0,8 \mathrm{a}$ & $0,5 a$ & $0,9 a$ & $0,7 a$ & $0,4 a$ \\
\hline $1,5+1,5$ & $0,5 a b$ & $0,7 a$ & - & $0,5 b$ & $0,7 a$ & $0,5 a b$ & $0,6 a$ & $0,6 a$ & $0,4 a$ \\
\hline $3,0+3,0$ & $0,0 \mathrm{~b}$ & $0,2 b$ & - & $0,1 \mathrm{c}$ & 0,36 & $0,3 b c$ & $0,1 b$ & $0,3 b$ & $0,3 a$ \\
\hline $6,0+6,0$ & $0,0 \mathrm{~b}$ & $0,0 b$ & - & $0,0 \mathrm{c}$ & $0,1 b$ & $0,2 \mathrm{c}$ & $0,0 b$ & $0,0 \mathrm{c}$ & $0,0 \mathrm{~b}$ \\
\hline
\end{tabular}

(1) Primeira calagem: 1974; segunda: 1978.

(2) Profundidade de amostragem do solo, em centimetro.

(3) Teste de Tukey a 5\%, sendo as médias comparáveis no sentido vertical, dentro de ano agrícola; espaços em branco representam falta de amostragem. 
QUADRO 2. Valores médios de P no solo, por nível de calcário e por ano agrícola, obtidos no ensaio permanente com o algodoeiro, em Guaira, SP

\begin{tabular}{|c|c|c|c|c|c|c|c|c|c|c|}
\hline \multirow{3}{*}{$\begin{array}{c}\text { Caicårio } \\
\text { aplicado (1) }\end{array}$} & \multicolumn{8}{|c|}{ P no solo, em análises anuais } & & \\
\hline & \multicolumn{2}{|c|}{$1978 / 79$} & \multicolumn{2}{|c|}{$1979 / 80$} & \multicolumn{2}{|c|}{$1980 / 81$} & \multicolumn{2}{|c|}{$1981 / 82$} & \multicolumn{2}{|c|}{ Médias } \\
\hline & (a) (2) & (b) & (a) & (b) & (a) & (b) & (a) & (b) & (a) & (b) \\
\hline t/ha & & & & & & & & & & \\
\hline $0+1,5$ & 5,5 & $18,8 \mathrm{C}\left({ }^{3}\right)$ & 5,3 & $19,0 \mathrm{~b}$ & 7,5 & $20,3 b$ & 8,5 & 20,0 & 6,7 & $19,5 \mathrm{C}$ \\
\hline $1,5+1,5$ & 5,3 & $20,8 b$ & 5,5 & $20,8 b$ & 7,3 & $20,8 b$ & 6,8 & 21,8 & 6,2 & $21,0 \mathrm{~b}$ \\
\hline $3,0+3,0$ & 4,3 & $21,3 b$ & 4,8 & $21,5 b$ & 6,8 & $22,3 a b$ & 6,5 & 23,8 & 5,6 & $22,2 \mathrm{~b}$ \\
\hline $6,0+6,0$ & 5,3 & $26, \mathrm{Oa}$ & 5,0 & $26,8 a$ & 7,0 & $27,0 a$ & 7,0 & 27,0 & 6,1 & $26,7 a$ \\
\hline Médias & $5,1 B(3)$ & $2 i, 7$ & $5,1 \mathrm{~B}$ & 22,0 & $7,1 \mathrm{~A}$ & 22,6 & $7,2 \mathrm{~A}$ & 23,3 & 6,1 & 22,3 \\
\hline $\mathrm{CV} \%$ & 30,9 & 4,9 & 12,6 & $i 0,1$ & 15,7 & 10,6 & 18,6 & 14,9 & 19,8 & 10,9 \\
\hline
\end{tabular}

(1 Primeira calagern: 1974; segunda: 1978.

(2) Fóstoro extraído do solo pelo mítodo dc $\mathrm{H}_{2} \mathrm{SO}_{4} \quad 0,05 \mathrm{~N}$ (a) e pela resina trocadora de ânions, com 16 horas de exposição (b).

(3) Teste de Tukey a $5 \%$ : letras minüsculas diferentes discrimiram médias entre niveis de calcário (sentido vertical) e, letras maiúsculas, médias entre amostragens (sertido horizontal).

O teor de fósforo extraído pela resina mostrou-se acentuadamente mais elevado, superando em cerca de quatro vezes aquele retirado pelo ácido sulfúrico diluído. O P-resina nas análises das parcelas com dose máxima de calcário sempre foi superior aos demais tratamentos. $\mathrm{Na}$ análise conjunta dos quatro anos, notou-se nítida tendência para crescimento do P-resina com o uso de calcário, além de boa repetitividade dos resultados analíticos.

Já o teor de fósforo exiraído pelo ácido sulfúrico diluído não se relacionou de forma alguma com a calagem empregada, tendo demonstrado precária repetitividade de resultados através dos anos: as últimas análises efetuadas acusaram valores de $P$ estatisticamente mais elevados do que os anteriores, a despeito de terem as amostras de solo sido coletadas sempre fora da faixa de adubação mineral.

\subsection{Resultados de produção}

As produções médias de algodão em caroço, observadas por nivel de calcário e de adubação com superfosfato simples, são apresentadas no quadro 3, assim como os resultados de análises de variâncias obtidos por ano agrícola. Por falta de resposta significativa, não se consideraram os dados referentes à adubação potássica. 
QUADRO 3. Resultados médios de produção de algodāo em caroço ( $\mathrm{kg} / \mathrm{ha}$ ), obtidos por nivel de calagem e de adubação com superfosfato simples e dados de análises estatisticas na segunda fase do ensaio permanente de Gualra, SP

\begin{tabular}{|c|c|c|c|c|}
\hline \multirow{2}{*}{$\begin{array}{l}\text { Calcário } \\
\text { aplicado (1) }\end{array}$} & \multicolumn{3}{|c|}{ Superfosfato simples (kg/ha/ano) } & \multirow{2}{*}{ Médias } \\
\hline & 0 & 300 & 600 & \\
\hline t/ha & \multicolumn{4}{|c|}{$1978 / 79$} \\
\hline $0+1,5$ & $496 \mathrm{~b}\left({ }^{2}\right)$ & $1.006 a b$ & $1.181 \mathrm{a}$ & $895 \mathrm{D}$ \\
\hline $1,5+1,5$ & $1.000 \mathrm{~b}$ & $1.243 a b$ & $1.618 \mathrm{a}$ & $1.287 \mathrm{C}$ \\
\hline $3,0+3,0$ & $1.785 b$ & $2.329 a$ & $2.561 a$ & $2.216 \mathrm{~B}$ \\
\hline $6,0+6,0$ & $2.481 \mathrm{a}$ & $2.629 a$ & $2.816 a$ & $2.642 \mathrm{~A}$ \\
\hline Média & $1.434 b$ & $1.802 \mathrm{a}$ & $2.044 a$ & 1.760 \\
\hline \multicolumn{5}{|l|}{$C V=24,8 \%$} \\
\hline & \multicolumn{4}{|c|}{$1979 / 80$} \\
\hline $0+1,5$ & $454 b$ & $1.116 a$ & $1.294 \mathrm{a}$ & 955D \\
\hline $1,5+1,5$ & $1.243 b$ & $1.596 \mathrm{ab}$ & $1.859 \mathrm{a}$ & $1.566 \mathrm{C}$ \\
\hline $3,0+3,0$ & $1.869 b$ & $2.549 a$ & $2.494 a$ & $2.304 \mathrm{~B}$ \\
\hline $6,0+6,0$ & $2.820 \mathrm{a}$ & $3.180 a$ & $2.974 a$ & $2.99+A$ \\
\hline Média & $1.596 b$ & $2.110 a$ & $2.155 a$ & 1.954 \\
\hline \multicolumn{5}{|l|}{$C V=20,4 \%$} \\
\hline & \multicolumn{4}{|c|}{$1980 / 81$} \\
\hline $0+1,5$ & $359 b$ & $1.105 \mathrm{a}$ & $1.434 \mathrm{a}$ & $966 \mathrm{D}$ \\
\hline $1,5+1,5$ & $945 b$ & $1.464 a$ & $1.695 a$ & $1.368 \mathrm{C}$ \\
\hline $3,0+3,0$ & $1.504 b$ & $2.023 a$ & $2.434 a$ & $1.987 \mathrm{~B}$ \\
\hline $6,0+6,0$ & $2.170 b$ & $2.664 a$ & 2.426ab & $2.420 \mathrm{~A}$ \\
\hline Média & $1.244 b$ & $1.814 \mathrm{a}$ & $1.997 \mathrm{a}$ & 1.685 \\
\hline \multicolumn{5}{|l|}{$C V=19,9 \%$} \\
\hline & \multicolumn{4}{|c|}{$1981 / 82$} \\
\hline $0+1,5$ & $234 c$ & $978 b$ & $1.334 a$ & $848 \mathrm{C}$ \\
\hline $1,5+1,5$ & $625 b$ & $1.299 a$ & $1.603 a$ & $1.175 \mathrm{C}$ \\
\hline $3,0+3,0$ & $1.140 b$ & $1.796 \mathrm{a}$ & $2.036 a$ & $1.658 \mathrm{~B}$ \\
\hline $6,0+6,0$ & $1.811 b$ & $2.104 a b$ & $2.235 \mathrm{a}$ & $2.050 \mathrm{~A}$ \\
\hline Média & $953 b$ & $1.544 \mathrm{a}$ & $1.802 a$ & 1.433 \\
\hline$C V=9,2 \%$ & & & & \\
\hline
\end{tabular}

(1) Primeira calagem: 1974; segunda: 1978.

(2) Letras năo comuns simbolizam classes estatf́sticas diferentes, pelo teste de Tukey a $5 \%$. As médias gerais para superfosfato simples, ou suas médias dentro de niveis de calcário, são comparáveis no sentido horizontal por meio de letras minúsculas; as médias gerais para calcário, no sentido vertical, por letras maiúsculas. 
Como se pode notar, o efeito da reaplicação do calcário sobre a produção de algodão foi de natureza linear durante todo o período de estudo, embora no quarto ano (1981/82), as duas menores doses, que sempre proporcionaram as mais baixas produtividades, não tenham diferido estatisticamente entre si. Pela figura 1, pode-se observar que as correçōes do indice $\mathrm{pH}$ proporcionadas pelas referidas doses também foram insuficientes, enquanto foram significativas para as doses maiores, à semelhança do que ocorreu com a produtividade do algodoeiro.

Ainda no quadro 3 , nota-se que o efeito do acúmulo anual de superfosfato simples foi de natureza quadrática, uma vez que a dose máxima proporcionou, na maioria dos anos, apenas pequenos acréscimos de produtividade em relação à dose básica. Embora a testemunha sem superfosfato tenha quase sempre diferido estatisticamente dos tratamentos adubados, o algodoeiro reagiu pouco à aplicação do adubo no nivel máximo de calagem, em especial nos dois primeiros cultivos. A análise conjunta dos quatro anos - Figura 3 - revela que, enquanto o acúmulo de superfosfato chega a triplicar a produção de algodão em solo ácido (nivel $0+1,5$ tha de calcário), pode-se obter alto nivel de produtividade das plantas em condiçōes de adequada correçāo da acidez (nível $6+6 t / h a$ ), com pouco ou mesmo sem uso do adubo.

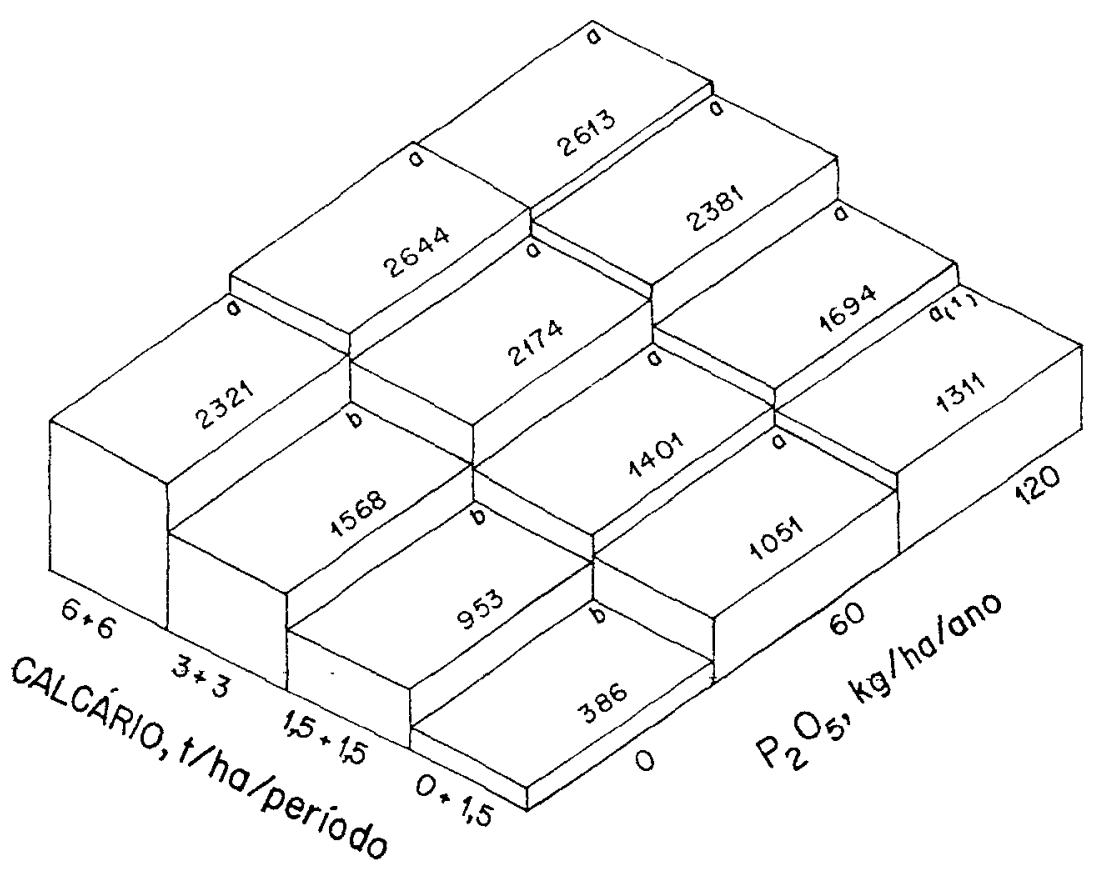

FIGURA 3. Influência da interação entre calagem e adubação com superfosfato simples sobre a produtividade do algodoeiro, observada na média de quatro cultivos sucessivos, no ensaio permanente de Guaira, SP. (1) Teste de Tukey a $5 \%$ ( $\Delta=350 \mathrm{~kg} / \mathrm{ha}$ ). 
Relações de substituição semelhantes foram detectadas por MIKKELSEN et al. (1963), trabalhando com algodão, e por VIDOR \& FREIREE (1972), com soja. QUAGGIO et al. (1982), por sua vez, consideram que, além do acesso a mais fósforo solúvel, as plantas em solo corrigido podem explorar maior volume de solo. Embora no presente trabalho não se tenha acompanhado o desenvolvimento do sistema radicular das plantas, um estudo de correlação entre o teor de $\mathrm{P}$ e o índice $\mathrm{pH}$, efetuado com dados médios de análises de terra, considerando ano como repetição, vem reforçar o primeiro aspecto, qual seja, o de maior solubilidade do fósforo no solo corrigido. A figura 4 mostra que o teor de P-resina, na média dos quatro anos de estudo, cresceu de forma linear e significativa com o valor do $\mathrm{pH}$ em água $\left(r=0,812^{\star *}\right)$, independentemente da adubação, uma vez que as amostras foram colhidas fora das linhas de plantio. Considerando que tal relacionamento possa constituir eficiente controle prático na avaliação do fósforo disponivel às plantas, conforme propōem FUZATTO \& CAVALERI (1966), o método da resina mostra-se, nesse aspecto, superior ao do ácido sulfúrico diluído ( $r=$ $-0,399 \mathrm{~ns}$ ), pelo menos no latossolo roxo rico em sesquióxidos e em matéria orgânica do presente trabalho.

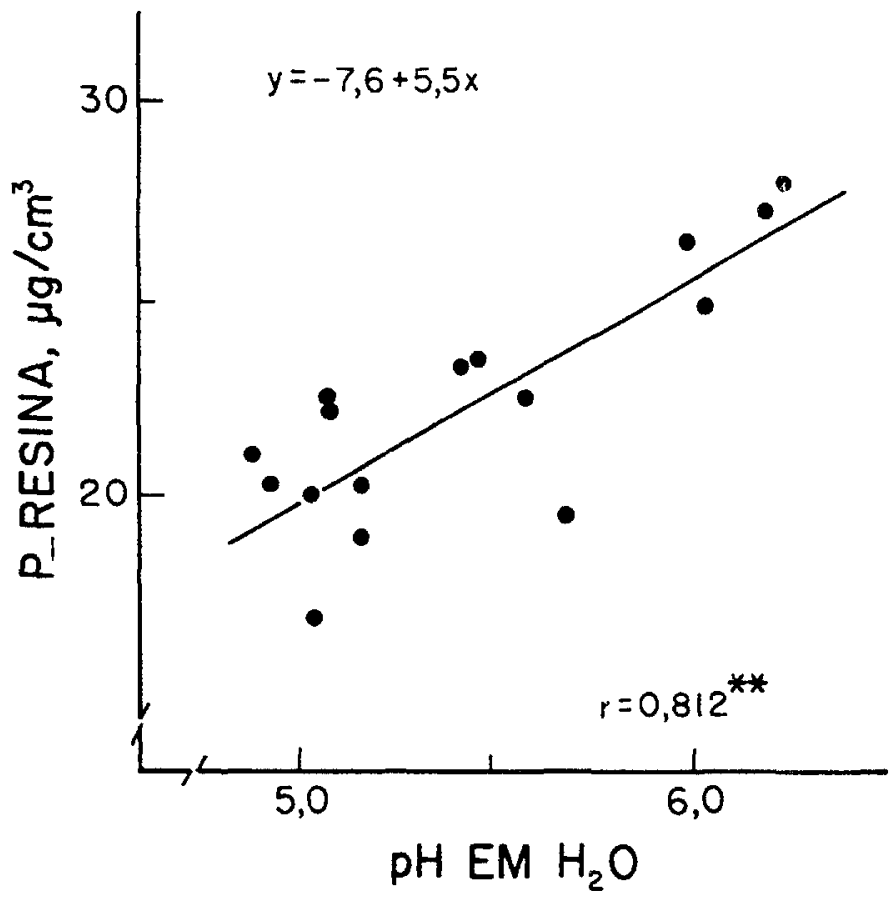

FIGURA 4. Relação entre $P$ extraído pela resina trocadora de ânions e $\mathrm{pH}$ em $\mathrm{H}_{2} \mathrm{O}$ da análise quimica de amostras de solo colhidas durante os quatro anos sucessivos, no ensaio permanènte de calagem com o algodoeiro, em Guaíra, SP. 


\subsection{Resultados de análise foliar}

Em funçăo do bom desenvolvimento das plantas obtido, inclusive no tratamento testemunha, foi possivel coletar folhas para análise quimica em todas as parcelas nos cultivos de 1979/80 e 1980/81, ou seja, no segundo e no terceiro ano da reaplicação de calcário. Nos quadros 4 e 5, encontram-se os teores médios de macronutrientes e micronutrientes e os resultados de suas análises estatisticas.

- calcário dolomítico concorreu para aumentar sensivelmente as concentraçóes de $\mathrm{Mg}$ e $\mathrm{Ca}$ do limbo foliar, e para diminuir os teores de $\mathrm{K}, \mathrm{Fe}$ e $\mathrm{Mn}$, nos dois anos de estudo. Quanto à concentração de $\mathrm{P}$, embora o calcário tenha proporcionado acréscimos superiores aos da própria adubação fosfatada, seu efeito só foi significativo no segundo ano agricola (1979/80). Confirmam-se, em linhas gerais, resultados obtidos na primeira fase desse estudo (SILVA et al., 1980) e em trabalho recentemente concluído de calagem e de adubaçăo potássica (SILVA et al., 1984).

QUADRO 4. Concentrações médias de macronutrientes e de micronutrientes nas quintas folhas coletadas no segundo ano de cultivo do algodoeiro após a reaplicação de calcário, e resultados de análises estatísticas respectivas, obtidas no ensaio de calagem em Guaira, SP

\begin{tabular}{|c|c|c|c|c|c|c|c|c|c|c|}
\hline \multirow{2}{*}{ Tratamentos } & \multicolumn{10}{|c|}{ Nutrientes } \\
\hline & $N$ & $P$ & $\mathrm{~K}$ & $\mathrm{Ca}$ & $\mathrm{Mg}$ & $\mathrm{Fe}$ & Mn & $\mathrm{Cu}$ & Zn & B \\
\hline $\begin{array}{c}\text { Calcário } \\
\text { tha/periodo }\end{array}$ & & & $-\%$ & & & & & ppm - & & - \\
\hline $\begin{array}{r}0+1,5 \\
1,5+1,5 \\
3,0+3,0 \\
6,0+6,0\end{array}$ & $\begin{array}{l}3,65 \\
3,68 \\
3,63 \\
3,68\end{array}$ & $\begin{array}{l}0,266 b \\
0,276 b \\
0,290 b \\
0,324 a\end{array}$ & $\begin{array}{l}2,12 a \\
2,18 a \\
2,06 b \\
1,99 b\end{array}$ & $\begin{array}{l}2,02 b \\
1,91 b \\
2,11 b \\
2,62 a\end{array}$ & $\begin{array}{l}0,47 c \\
0,52 c \\
0,59 b \\
0,74 a\end{array}$ & $\begin{array}{l}225 a \\
133 b \\
119 b \\
124 b\end{array}$ & $\begin{array}{l}339 a \\
247 b \\
173 c \\
174 c\end{array}$ & $\begin{array}{l}6,7 \\
6,4 \\
6,5 \\
6,8\end{array}$ & $\begin{array}{l}27,8 \\
28,1 \\
28,9 \\
30,0\end{array}$ & $\begin{array}{l}41 \\
37 \\
33 \\
37\end{array}$ \\
\hline $\begin{array}{c}\text { d.m.s. }(\Delta, 5 \%) \\
\mathrm{CV} \%\end{array}$ & $\begin{array}{l}0,25 \\
8,1\end{array}$ & $\begin{array}{c}0,028 \\
10,7\end{array}$ & $\begin{array}{l}0,08 \\
12,6\end{array}$ & $\begin{array}{l}0,28 \\
14,4\end{array}$ & $\begin{array}{c}0,07 \\
14,7\end{array}$ & $\begin{array}{l}72 \\
53,3\end{array}$ & $\begin{array}{l}55 \\
26,3\end{array}$ & $\begin{array}{r}0,9 \\
15,7\end{array}$ & $\begin{array}{r}5,0 \\
19,1\end{array}$ & $\begin{array}{l}15 \\
40,6\end{array}$ \\
\hline $\begin{array}{c}\text { Superfosfato } \\
\text { simples } \\
\text { kg/ha/ano } \\
0 \\
300 \\
600\end{array}$ & $\begin{array}{l}3,62 \\
3,61 \\
3,74\end{array}$ & $\begin{array}{l}0,271 b \\
0,295 a \\
0,301 a\end{array}$ & $\begin{array}{l}2,26 a \\
2,03 b \\
1,96 b\end{array}$ & $\begin{array}{l}2,06 b \\
2,16 a b \\
2,28 a\end{array}$ & $\begin{array}{l}0,57 \\
0,58 \\
0,59\end{array}$ & $\begin{array}{l}200 a \\
131 b \\
120 b\end{array}$ & $\begin{array}{l}230 \\
241 \\
228\end{array}$ & $\begin{array}{l}6,9 a \\
6,6 b \\
6,4 b\end{array}$ & $\begin{array}{l}30,3 a \\
28,6 a b \\
27,1 b\end{array}$ & $\begin{array}{l}41 a \\
36 b \\
34 b\end{array}$ \\
\hline $\begin{array}{c}\text { d.m.s. }(\Delta, 5 \%) \\
\text { CV\% }\end{array}$ & $\begin{array}{l}0,21 \\
9,5\end{array}$ & $\begin{array}{l}0,011 \\
6,1\end{array}$ & $\begin{array}{c}0,16 \\
12,6\end{array}$ & $\begin{array}{l}0,16 \\
12,3\end{array}$ & $\begin{array}{c}0,04 \\
10,7\end{array}$ & $\begin{array}{l}23 \\
25,5\end{array}$ & $\begin{array}{l}25 \\
17,5\end{array}$ & $\begin{array}{l}0,3 \\
7,3\end{array}$ & $\begin{array}{r}1,7 \\
10,0\end{array}$ & $\begin{array}{c}4 \\
16,8\end{array}$ \\
\hline
\end{tabular}


QUADRO 5. Concentraçōes médias de macronutrientes e de micronutrientes nas quintas folhas coletadas no terceiro ano de cultivo do algodoeiro após a reaplicação de calcário, e resultados de análises estatísticas respectivas, obtidas no ensaio de calagem em Guaira, SP

\begin{tabular}{|c|c|c|c|c|c|c|c|c|c|c|}
\hline \multirow{2}{*}{ Tratamentos } & \multicolumn{10}{|c|}{ Nutrientes } \\
\hline & $N$ & $P$ & $K$ & $\mathrm{Ca}$ & $\mathrm{Mg}$ & $\mathrm{Fe}$ & $\mathrm{Mn}$ & $\mathrm{Cu}$ & Zn & B \\
\hline \multicolumn{11}{|l|}{$\begin{array}{l}\text { Calcário } \\
\text { tha/perlodo }\end{array}$} \\
\hline $\begin{array}{r}0+1,5 \\
1,5+1,5 \\
3,0+3,0 \\
6,0+6,0\end{array}$ & $\begin{array}{l}4,62 \\
4,69 \\
4,33 \\
4,33\end{array}$ & $\begin{array}{l}0,340 \\
0,367 \\
0,357 \\
0,360\end{array}$ & $\begin{array}{l}2,31 a \\
2,32 a \\
2,13 a b \\
1,90 b\end{array}$ & $\begin{array}{l}2,41 b \\
2,31 b \\
2,36 b \\
2,67 a\end{array}$ & $\begin{array}{l}0,51 c \\
0,54 c \\
0,64 b \\
0,79 a\end{array}$ & $\begin{array}{l}589 a \\
394 a b \\
369 b \\
354 b\end{array}$ & $\begin{array}{l}458 a \\
397 a \\
271 b \\
314 b\end{array}$ & $\begin{array}{l}8,1 \\
8,1 \\
7,6 \\
7,3\end{array}$ & $\begin{array}{l}27,4 \\
29,1 \\
28,5 \\
27,8\end{array}$ & $\begin{array}{l}28 \\
28 \\
30 \\
29\end{array}$ \\
\hline $\begin{array}{c}\text { d.m.s. }(\Delta, 5 \%) \\
\text { CV\% }\end{array}$ & $\begin{array}{l}0,43 \\
10,5\end{array}$ & $\begin{array}{c}0,061 \\
19,1\end{array}$ & $\begin{array}{c}0,24 \\
12,0\end{array}$ & $\begin{array}{l}0,14 \\
6,4\end{array}$ & $\begin{array}{c}0,08 \\
13,3\end{array}$ & $\begin{array}{l}200 \\
52,0\end{array}$ & $\begin{array}{l}66 \\
19,9\end{array}$ & $\begin{array}{r}2,8 \\
40,5\end{array}$ & $\begin{array}{r}4,1 \\
16,0\end{array}$ & $\begin{array}{c}5 \\
19,8\end{array}$ \\
\hline \multicolumn{11}{|l|}{$\begin{array}{l}\text { Superfosfato } \\
\text { simples } \\
\text { kg/ha/ano }\end{array}$} \\
\hline $\begin{array}{r}0 \\
300 \\
600\end{array}$ & $\begin{array}{l}4,28 b \\
4,60 a \\
4,60 a\end{array}$ & $\begin{array}{l}0,355 \\
0,351 \\
0,362\end{array}$ & $\begin{array}{l}2,35 a \\
2,15 b \\
1,99 c\end{array}$ & $\begin{array}{l}2,27 b \\
2,46 a \\
2,58 a\end{array}$ & $\begin{array}{l}0,57 b \\
0,63 a \\
0,66 a\end{array}$ & $\begin{array}{l}518 a \\
427 a b \\
335 b\end{array}$ & $\begin{array}{l}343 b \\
382 a \\
369 a b\end{array}$ & $\begin{array}{l}8,3 a \\
7,6 a b \\
7,4 b\end{array}$ & $\begin{array}{l}29,5 a \\
28,3 b \\
26,8 c\end{array}$ & $\begin{array}{l}30 \\
27 \\
29\end{array}$ \\
\hline$\underset{\text { CV\% }}{\text { d.m.s. }(\Delta, 5 \%)}$ & $\begin{array}{l}0,25 \\
9,4\end{array}$ & $\begin{array}{c}0,024 \\
11,4\end{array}$ & $\begin{array}{c}0,13 \\
10,0\end{array}$ & $\begin{array}{l}0,14 \\
9,7\end{array}$ & $\begin{array}{c}0,04 \\
11,7\end{array}$ & $\begin{array}{l}179 \\
70,0\end{array}$ & $\begin{array}{l}35 \\
15,8\end{array}$ & $\begin{array}{r}0,8 \\
17,8\end{array}$ & $\begin{array}{l}1,2 \\
6,8\end{array}$ & $\begin{array}{c}3 \\
14,6\end{array}$ \\
\hline
\end{tabular}

A adubação com superfosfato simples, em geral, proporcionou aumento no teor de $\mathrm{Ca}$ e diminuição em $\mathrm{K}, \mathrm{Fe}, \mathrm{Cu}$ e $\mathrm{Zn}$; em um ano ou outro, aumentou significativamente, também, as concentrações de P, Mg e Mn, e diminuiu as de B. Quanto aos macronutrientes, resultados similares foram obtidos em trabalhos anteriores, o que confirma a importância de se utilizar o superfosfato simples como fornecedor de $\mathrm{P}$ e Ca e estimulador da absorção de $\mathrm{Mg}$, conforme trabalhos de SILVA et al. $(1979,1981)$. Quanto à análise de micronutrientes, nota-se um efeito geral depressivo da adubação, que, na primeira fase do estudo, limitou-se a Fe e Al (SILVA et al., 1984), mas que, com o acúmulo anual da adubação, estendeu-se a $\mathrm{Zn}, \mathrm{B}, \mathrm{Cu}$ e $\mathrm{Mn}$. Aparentemente, esse efeito foi mais consistente do que 0 da própria calagem. Entretanto, sintomas iniciais de deficiência de $\mathrm{K} \mathrm{e} \mathrm{B}$ em plantas foram observados apenas em algumas parcelas bem adubadas com fósforo e calcariadas, coincidentemente no segundo e terceiro anos agrícolas, os de mais alta produtividade. Trabalhos anteriores, conduzidos em solos mais pobres em argila e matéria orgânica, já indicavam a necessidade de adequar as adubações potássica e boratada, quando da correção de terras ácidas para o algodoeiro (CARVALHO, 1980, e SILVA, 1983). 


\section{CONCLUSÕ̃ES}

Do exposto, podem-se ressaltar os seguintes aspectos:

1) O latossolo roxo estudado, rico em argila $(66 \%)$ e em matéria orgânica $(4,1 \%)$ apresentou alta resistência em alterar o valor analítico de seu $\mathrm{pH}$ em função da calagem, quando o valor original era igual ou superior a 5,2.

2) Desde o primeiro ano agricola, detectou-se lixiviação de $\mathrm{Ca}$ e de $\mathrm{Mg}$ do calcário para camadas subsuperficiais do solo, com conseqüente melhoria do $\mathrm{pH}$ em profundidade, proporcional à quantidade de corretivo utilizada.

3) A produtividade das plantas cresceu linearmente com a reaplicação de calcário, até a dose de 6 t/ha, e o efeito do acúmulo anual de superfosfato simples, até à dose de $120 \mathrm{~kg} / \mathrm{ha} / \mathrm{ano}$, foi de natureza quadrática.

4) A resposta do aigodoeiro à adubação fosfatada diminuiu com a quantidade de corretivo adotada, configurando a já conhecida interação negativa entre as duas práticas.

5) O método da resina trocadora de ânions mostrou-se mais adequado do que o do ácido sulfúrico diluído na extração do fósforo do solo, tendo em vista a boa repetitividade dos resultados analiticos duranie os quatro anos de estudo e a estreita correlação que apresentou com o indice $\mathrm{pH}$ da análise de terra.

6) Decréscimos significativos na concentração de $\mathrm{K}, \mathrm{Fe}, \mathrm{Mn}, \mathrm{Cu}, \mathrm{Zn}$ e $\mathrm{B}$ no limbo foliar do algodoeiro, devidos à calagem e à adubação fosfatada, confirmam a necessidade de se atentar para uma possivel deficiência dos citados elementos, especialmente de $\mathrm{K}$ e de $\mathrm{B}$, quando se busca corrigir solos ácidos e pobres em nutrientes para essa cultura.

\section{SUMMARY}

\section{EFFECT OF LIMING UPON COTTON RESPONSE \\ TO ORDINARY SUPERPHOSPHATE}

After four years of the first lime application in a permanent field experiment with cotton, the liming was reapplied with the same previous levels $(1.5,3.0$ and $6.0 \mathrm{t} / \mathrm{ha}$ ) of dolomitic limestone, except for the test treatments where the lowest dose was used. Annual fertilizations of $60 \mathrm{~kg} \mathrm{~N} / \mathrm{ha}, 0,60$ and $120 \mathrm{~kg} \mathrm{P} \mathrm{P}_{2} \mathrm{O}_{5} / \mathrm{ha}$ and 40 and $80 \mathrm{~kg} \mathrm{~K} \mathrm{O}_{2} / \mathrm{ha}$, were carried out. The experiment was conducted in an acid, clayey soil, rich in organic matter: a Dusky-Red Latosol. The pH value at the superficial soil layer was kept around 6.0, with the reapplication of 6.0 t/ha of limestone, and near the value of 5.5 , at $20-40 \mathrm{~cm}$ depth, due to leaching of alkaline cations. Cotton yields and values of $\mathrm{pH}$ and $\mathrm{Ca}+\mathrm{Mg}$ from the soil analysis increased linearly with liming. However, the effect of ordinary superphosphate upon cotton yield, decreased 
with liming, showing a negative correlation. The data of phosphorus extracted by anion-exchange resin method showed low variability and high correlation with the soil $\mathrm{pH}$ values, during the four years of study. For this reason, the ion-exchange resin method was considered more adequate than the $0.05 \mathrm{~N}$ $\mathrm{H}_{2} \mathrm{SO}_{4}$ method. Appreciable decreases in leaf concentrations of some macronutrients and micronutrients were observed with the high application of limestone and superphosphate, as a rule to recover acid soils, and indicated the need of readjusting the cotton fertilization with regard to the levels of $K$ and $B$, specially.

Index terms: dolomitic limestone; ordinary superphosphate; correlation between liming and phosphorus; leaching of basic cations; and leaf blades analyses.

\section{REFERÊNCIAS BIBLIOGRÁFICAS}

ADAMS, F. Response of cotton to lime in field experiments. Alabama, Agr. Exp. Sta., 1968. 23p. (Bull, 376)

; PEARSON, R.W. \& DOSS, B.O. Relative effects of acid subsoil on cotton yields in field experiments and cotton roots in growth-chamber experiments. Agronomy Journal, 59(5):453-456, 1967.

CARVALHO, L.H. Efeitos dá calagem e da adubação boratada sobre o algodoeiro (G. hirsutum L.) cultivado em Latossolo Vermelho-Amarelo fase arenosa. Piracicaba, Escola Superior de Agricultura "Luiz de Queiroz", 1980. 64f. Dissertação (Mestrado).

FUZATTO, M.G. \& CAVALERI, P.A. Correlação entre a resposta do algodoeíro à adubação fosfatada e a análise química do solo, nas condições do Estado de São Paulo. Bragantia, Campinas, 25:407-420, 1966.

JONES, U.S. \& BARDSLEY, C.E. Phosphorus nutrition. In: ADVANCES in production and utilization of quality cotton: principles and practices. Ames, The lowa State University Press, 1968. p.213-254.

MENGEL, K. \& KIRKBY, E.A. Principles of plant nutrition. Bern, International Potash Institute, 1978. 593p.

MIKKELSEN, D.S.; FREITAS, L.M.M. \& McCLUNG, A.C. Efeitos da adubação mineral na produção de algodão, milho e soja em três solos de campo cerrado. São Paulo, IBEC Research Institute, 1963. 48p. (Boletim, 29)

QUAGGIO, J.A.; MASCARENHAS, H.A.A. \& BATAGLIA, O.C. Resposta da soja à aplicação de doses crescentes de calcário em Latossolo roxo distrófico de cerrado. II. Efeito residual. Revista Brasileira de Ciência do Solo, 6(2):111-124, 1982.

RAIJ, B. van. Avaliação da fertilidade do solo. Piracicaba, Instituto da Potassa \& Fosfato. São Paulo, Instituto Internacional da Potassa, 1981. 142p.

; CAMARGO, A.P.; CANTARELLA, H. \& SILVA, N.M. Alumínio trocável e saturação em bases como critérios para recomendação de calagem. Bragantia, Campinas, 42:149-156, 1983. 
RAlJ, B. van; FEITOSA, C.T. \& SILVA, N.M. Comparação de quatro extratores de fósforo de solos. Bragantia, Campinas, 43:17-29, 1984.

\& ZULLO, M.A.T. Métodos de análise de solos para fins de fertilidade. Campinas, Instituto Agronômico, 1977. 16p. (Circular, 63)

SILVA, N.M. Acidez do solo e calagem para o algodoeiro. In: REUNIĀO BRASILEIRA DE FERTILIDADE DO SOLO, 15., Campinas, 1982. Simpósio sobre acidez e calagem no Brasil, coord. por Bernardo van Rajj, Ondino Cleante Bataglia e Nelson Machado da Silva. Campinas, Sociedade Brasileira de Ciência do Solo, 1983. p.259-276.

- _- CARVALHO, L.H.; HIROCE, R. \& KONDO, J.I. Resposta do algodoeiro à aplicação de calcário e de cloreto de potássio. Bragantia, Campinas, 43:643-658, 1984.

; FERRAZ, C.A.M.; RODRIGUES FILHO, F.S.O. \& HIROCE, R. Emprego de calcário e de superfosfato simples na cultura do algodoeiro em solo argiloso ácido. Bragantia, Campinas, 39:39-50, 1980.

-; GRIDI-PAPP, I.L; CIA, E; CARVALHO, L.H. \& HIROCE, R. Comportamento das variedades de algodoeiro IAC 13-1, IAC 16 e IAC 17 em ensaio permanente de adubação com superfosfato simples. Bragantia, Campinas, 38:71-81, 1979.

—-; RODRIGUES FILHO, F.S.O. \& HIROCE, R. Uso de misturas de adubos contendo ou näo enxofre na adubação do cultivar IAC 16 de algodoeiro. Bragantia, Campinas, 40:167-178, 1981.

TISDALE, S.L. \& NELSON, W.L. Soil fertility and fertilizers. 3.ed. New York, Collier MacMillan International Editions, 1975. 430p.

VIOOR, C. \& FREIRE, J.R.J. Relação de substituição entre calcário e fósforo aplicados ao solo na cultura de soja. Agronomia Sulriograndense, Porto Alegre, 8:187-193, 1972. 